\title{
Framework for Improving Usability of Learning Management Systems by Integrating Pedagogical Agent
}

\author{
Beryl Adhiambo \\ Odhiambo \\ Computing Department \\ Jomo Kenyatta University of \\ Agriculture and Technology
}

\author{
George Okeyo \\ Computing Department \\ Jomo Kenyatta University of \\ Agriculture and Technology
}

\author{
Wilson Cheruiyot \\ Computing Department \\ Jomo Kenyatta University of \\ Agriculture and Technology
}

\begin{abstract}
The research intended to develop a framework for improving the usability of Learning Management Systems by integrating pedagogical agent. The study adopted usability heuristics as the key factors for enhancing the usability of an LMS through a conversational pedagogical agent. The first objective explored various techniques available for enhancing the usability of the LMS. The techniques includes Learnability, efficiency, and satisfaction are but a few techniques used to measure usability of a web-based system. The second objective examined a variety of ways the pedagogical agent can improve the usability of the LMS. The research recognized that a pedagogical agent could improve the usability of an LMS by making studying more interesting and increasing student to instructor interaction to support active learning. The third objective was for the designing of a suitable framework for improving the usability of an LMS. The fourth objective intended to evaluate the impact of the computer-based pedagogical agent in the LMS. The research established that the conversational pedagogical agent increased human to computer interaction, makes learning more effective and enjoyable and supports self-paced active learning. An experimental research design was adopted in carrying out the research. A conversational pedagogical agent (Melsyanne) was deployed as a prototype to improve the effective use of an LMS. The target population comprised of 3 HODs, 12 Instructors and 82 Students from three randomly selected higher learning institutions within Nakuru Municipality. Data was collected using questionnaires and analyzed through frequencies and percentages using SPSS. The results were presented using tables, column graphs and pie-charts generated by MS Excel application software. The findings constitute the knowledge pool, from which future research can borrow and add in their research study.
\end{abstract}

\section{General Terms}

Human-Computer Interaction (HCI), Usability, Course Management System (CMS), Conversational Pedagogical Agent.

\section{Keywords}

Improving Usability, Learning Management System (LMS), Pedagogical Agent.

\section{INTRODUCTION}

Learning Management Systems (LMS) are course management application programs that are widely used to extend learning services to higher learning institutions. LMS are normally used by institutions to manage education for students taking regular courses or distance learning programs. The main aim of using these systems is to make sense of knowledge acquired and learned to improve ways of performing the task. Higher institutions use these systems for instructing and as control tools for their students. The system supports' traditional educational approach based on the management, evaluation, monitoring and administering education from the teachers to learners [2]. Educational technology goes hand in hand with pedagogy when it comes to training and acquiring knowledge. Various institutions have utilized Learning Management Systems to set up web-based learning content and create opportunities to cross cultural borders and distribute learning on a global scale [3]. Therefore an LMS is more effective and efficient when it is easy to use, interactive and flexible [4]. The integration of a pedagogical agent to an LMS can improve its effective use through Human-Computer Interaction.

A pedagogical agent is an animated life-like character in a multimedia learning environment that facilitates the learning process [5]. They are developed by software engineers and artificial engineering to explain a concept or demonstrate the procedure for performing a variety of simulated tasks [6].

The rising challenge for program developers and Human Computer Interaction (HCI) researchers is to develop software tools for making e-learning effective. Learning Management Systems provide information where students take the time to go through the course and have to recall the theoretical concept rather than consulting their instructors for additional information with the aim of deeply understanding a topic and feel in control of the learning through the use of computerbased agents.

According to [7], the effective use of the Learning Management Systems supports collaborative learning and social interactions. However, the psychological needs and clues to hand on experience during personal studies are not catered for since students are not guided physically or monitor by their instructors [8].

Learning Management systems have extended learning services to a vast environment. Users of an LMS that is inadequate usually feel confused, frustrated, anxious, and reduce the interest of learning. The major contribution of the failure to implement Course Management System for higher learning is inadequate usability. Usability of LMS influences how the users assess their learning experience, if the usability of Learning Management System is unfriendly, students fail to make effective use the system [9]. The main problem the students encounter when using an LMS as the main channel of education is the delay of feedback on their study queries. Researching from various web sources to get information exposes them to wrong or unreliable information that affects their studies. For quick and correct learning, the immediate response from the instructors should be able to give timely answers to the learner's study queries. We can therefore 
comfortably say that immediate feedback is the best solution to correct and quick learning. It also motivates and supports the study process of the learners [10]. When instructors influence the academic and socially interact with the learners, the learning outcome is usually more effective and efficient. Real-time student to instructor interaction is very vital to the trajectory of learning that will eventually lead to employment [11], [12], and [13]. Although physical availability is impractical through LMS, technology can be used to develop a creative interactive program which is capable of communicating with the students as if the teacher is present. There is need to integrate a conversational pedagogical agent to an LMS to accomplish a better learner-instructor interaction. To make an LMS a better all-around program that is easy to use, interactive, enjoyable and thorough in its functions of bringing out more realistic computer systems experts who will require less time in trying to figure out technical ideas from prose and large volumes of books. The aim is to make learning more interactive, exciting and directions more personalized as would be in a real life situation through simulations. It is even more necessary that learning moves with the times, make the learner feel much more in control, and updated when using the Learning Management System.

\section{LITERATURE REVIEW}

\subsection{Usability heuristics of Learning Management Systems}

The term usability means that users can use a tool or system to accomplish a task with satisfaction and ease. In the user's point of view, the use of Learning Management System is controlled by the learner cognitive and perceptual abilities [14]. The better human-computer interaction with learning management systems, the easier it is to use and gain greater satisfaction within systems and their tools. Usability can improve the learning experience for learners [15] as well as educational performance. Therefore, a good design with usability study is a crucial component in the development of a Learning Management System. The attitude of the user towards the system, its flexibility, effectiveness in use and learnability of the system are four critical areas to look for when assessing the usability of the system [16]. Usability is a technique used for experimenting the quality of a system and how easy it is for the user to interact with its interface. The term "usability" refers to methods for improving ease of use during the design process. There are five quality components to define usability; Learnability, efficiency, memorability, errors and satisfaction [1]. Therefore, Usability is the degree to which a particular system is used by to accomplish specific goals with effectiveness, efficiency, and satisfaction.

\subsection{Usability Features of Course Management System}

The effectiveness and satisfaction of online Learning Management System depend on its usability features. These features include; the system interface/layout design, ease of use and navigation, the speed of use, learnability, user satisfaction, system functionality, and usefulness. [17] categorized three main system features provided by learning management system as explained; 1). Instructional elementsused in course management such as survey manager, grade books, syllabus builder, edit. Update or remove announcements, edit staff details. Alter or add course tutorial and personal management tool. Communicate to an individual or a group through email and the message feature within the
Blackboard. 2). Interactive features like discussion boards, chartroom, digital drop box among others support data transfer and communication within the LMS. 3). Visual features to make the LMS look appealing are presented by interface layout and design, font styles and colors among others.

\subsection{Approaches to usability enhancement in Learning Management System}

LMS automates the learning program as compared to the brick and mortar education mode of delivery. Therefore, it requires extra effort in studying and personal motivation of the learner to excel in their studies. [18] Considered the Nielsen's usability heuristics as the main method for enhancing usability in eLearning. A pedagogical agent is a tool that can be used to assimilate human actions for performing a task. This program can monitor activities taking place within the LMS through tracking the performance of the learners, identifying errors or providing feedback. The agents can also offer support in conveying course information to the learners according to the course curriculum, the intended mode of delivery, planning, and control of the course content. The agent can be used for tutorial remediation to extend learning and course coverage. Student models can provide individualized learning in the system [19]. Incorporating pedagogical interface agents or virtual humans for training purpose makes learning more interesting and engaging as compared to an LMS that only supports upload and download of documented tutorials. Existing Pedagogical agents like Soar Training Virtual Environment (Steve), and Agent the for Distributed Learning Environment (Adele), was introduced by the Central for Advance Research in Technology for Education (CARTE) at the University of Southern California (USC). The primary aim of these agents was to provide individual and personal training for LMS [20].

\subsection{Types of pedagogical agents used in LMS}

Teachers and learners can use pedagogical agents to expand documented academic learning to the intelligent learning environment and teaching. They are categorized into three major types; Digital Education, Digital tutor, and Digital secretary [21].

\subsection{Benefits of pedagogical agents in higher learning institutions}

The use of pedagogical agents has massively been integrated into the business and learning the environment and is likely to transfer traditional way of performing a task to mobile as well as blended intellectual settings [22]. The technology provides pedagogical agents as dynamic, and speaking avatars are in mass market use. Pedagogical agents make educational resources richer and more engaging experience than reading lines of text on the screen.

The web services prevent storage of bulky information on the agent by providing other sources of online teaching materials. Innovative learning through agents that supports problembased learning motivates students to customize and personalize their learning programs. Conversational agents are useful if it provides personal relation and discloses information to the pedagogical agents. Conversational agents are used to facilitating human-computer interaction through natural language processing. They provide information to users request and at times generate questions for the users to keep the conversation more interesting. Integrating such agent 
to the LMS encourages the learners to take control of their studies, make learning more interesting and majorly improve the usability of a Learning Management System.

\subsection{Challenges of Implementing Pedagogical Agent to the Learning Environment in Higher institutions}

The education setting requires the redefining the accepted role of the instructor and learner. The traditional ways of teaching assume students as not sufficiently knowledgeable people to fully practice the skills they have acquired in schools. This assumption strengthens the teacher's role as the core controller of learning practices with the aim of transferring predefined knowledge to the learners. Hence ending up to too much instructor's control in the learning process and leading to student boredom, poorly learning experience and demoralization. Teachers being the primary agents of change in the learning environment are resistant to adopt pedagogical innovations and technology [23]. The instructors have to content to three main factors with embracing technology; The psychological effect of change, learning to use the technology and rethinking their Pedagogical approach to facilitate more student's control in an educational environment using Web 2.0 tools and technologies. Teachers do not have a clear perception about the Pedagogical Learning Environment (PLE) concept, its implications, and benefits, hence making them hesitant to adopt and accept the idea.

\subsection{The impact of pedagogical agents among the instructors and learners}

Motivating students; Learning is motivated when the trainees observe models. Verbal encouragement together with task performing activities facilitates students' self-efficacy beliefs [24]. The pedagogical agent with sound features motivates the student to concentrate and become more interested in practical training to enable them to know how to operate computerized equipment technically. Intelligent programs act as professionals. Experts who exhibit extensive knowledge to perform activities better than average within a domain of a program are the same of the developers of the pedagogical agents. Keeping in mind that the agents are emotionless and their responses depend on the internal and external simulations [25].

\subsection{Research Gaps}

Learning Management System is incorporated in higher education institutions to distribute educational services to people both locally and internationally. Most courses offered are in the field of the Business, humanities, computing and technology. The mode of training entails the provision of course content through documents, presentations, word processing applications and spreadsheet programs. Formal education offered over the web through the use of presentations and videos, Google Docs and YouTube are uploaded and maintained by the course facilitators [26].

Despite the fact that trainers provide educational instructions through YouTube videos, presentations found in Google Docs and Course Management Systems, this training is teachercentered and passive [24]. Various sources present information in a different format and are not from a centralized source hence making it difficult to access the most reliable information intended for study purpose. The gap remains as to how the real-time interaction between the learner and the instructor can be achieved. The study intends to fill the gap by designing a framework that will guide on improving usability of an LMS by integrating a conversational pedagogical agent.

\subsection{Conclusion}

In summary, a good number of researchers agree that digital assimilated programs can improve the learning [21] However, there is little research done on how social conversational pedagogy agents are among the technical tools for enhancing the effective use of an LMS. These agents proved multimedia interaction between the instructor and the learner. In most cases, learners' need to physically interact with their instructors to explain/respond to their personal questions concerning a topic or study area. The use of conversational pedagogy agent can feel this gap by getting open questions from students and providing a timely response that matches the problem according to the agent's intelligence. Therefore, there is a need to cooperate in a conversational pedagogy agent to make learning easier, enjoyable, and self-centered to enable the student to take control of their learning and enhance the usability of a Learning Management System.

\section{RESEARCH METHODOLOGY}

The researcher adopted an experimental research design as an in-depth investigation of the study. An evaluation to find out if pedagogical agents can improve the usability of a Learning Management System was performed to support the subject. The study was carried out in Higher Learning Institution in Kenya within Nakuru County.

The research targeted the Head of departments, Instructors and the students from nine Institutions of Higher learning within Nakuru Municipality that uses the content management system. Radom sampling was adopted by writing names of all the institutions on paper after that three pieces of paper were selected from among the nine pieces at random. The three institutions automatically constituted the $30 \%$ of the total which was enough size in this study. The total number of the students 316 and the 53 instructors from the computing department in the three institutions was used to generate a sample of $30 \%$ of the total population. From this, a sample consisting of 16 instructors and 95 students from the three institutions. All the three Head of Departments for these institutions purposively sampled for inclusion in this study. Observation, questionnaires and interview schedule were the research instruments used for the study. Data collected was coded and entered in the Statistical Package for Social Sciences (SPSS) database. The charts were developed using Microsoft Excel application software. Descriptive statistics (frequencies and percentages) and inferential statistics (Pearson correlation coefficient and Regression analysis) were computed.

\section{DATA ANALYSIS, PRESENTATION, AND DISCUSSION}

\subsection{Pedagogical Agent}

Pedagogical agents are intelligent agents that provide individualized instructions to learners. They are potentially an important element in the instructional value in the instructional because they assume the role of mentor or tutor and increasing the learning value of LMS [27]. 


\subsection{How conversation pedagogical agent can improve usability of learning management system}

The most effective way of supporting Human Computer Interaction (HCI) is by allowing users freely express their questions and interest by texting or speaking to the agent [28]. These agents encourage interactions and give the user opportunity to take control of their learning by prompting questions or requesting for hints/ideas to performing a practical task. They also allow learner feel the virtual presence of the course facilitators.

Animated interface agents act as a target for increasing interest and attention of the user driven by speculated effect on human cognition and dialogue motivation [29]. These agents deliver interactive text-based dialogs by integrating computational linguistics techniques with the web as the communication channel and responding to statements made by the users through ordinary language [30]. A student can find learning more interactive and enjoyable when they are communicating with a conversational agent that has a "sense of humor" capability by recognizing humorous sentences from users and provide humoristic expression during dialogue [31]. The young generation feels more comfortable interacting with a person whom they are not so much attached to or an agent especially when they are searching for information concerning private issues that they cannot directly or easily discuss with their parents or instructors. However, conversational agents are at times subject to misuse and abuse triggered by learners [32].

\subsection{Conversational Pedagogical Agent}

In the current society, the spread of information has been gone global through the use of information technology and the internet. ICT has brought about the development of diverse ways of communication with computers through Human Computer Iteration (HCI). With conversational agents, the cognitive interfaces have improved ways in which users interact with computers for the purpose of acquiring knowledge, inquiring for information or entertainment purpose. Human beings are social in nature, and if computers assist humans in various functions, they will have to learn the human language [33]. The major advantage is that Conversational agents have linguistic intelligence due to their capability of interpreting words and use of Natural Language Processing (also called Computational Linguistics) ability. The pedagogical agent tends to match words from users' input and applies a metalinguistic ability to provide the appropriate response to the user. Natural Language Processing (NLP) is a branch of computer interaction linguistic and computer science concerned with the interaction between human (natural language) and computers. With the ability of a computer to understand the human language it becomes much easier to interact with them hence the conversational agents are considered as intelligent systems [34].

\subsubsection{Melsyanne Chatbot developed in AIML (Artificial Intelligence Markup Language) and its interpreter Program $O$ \\ A prototype of a conversational pedagogy agent (Melsyanne} Chatbot) was developed using Artificial Intelligence Markup Language (AIML) is an extension of XML-bases description language designed for developing natural software agents.

The prototype was developed to test if a conversational pedagogical agent can be used to improve the usability of a learning management system. This agent was used to by students for human computer interaction where a student could initiate a conversation by asking Melsyanne Chatbot unrestricted questions related to a lecture document uploaded in their Learning Management System. This agent provides a logical immediate response to the learners. The learners are also able to control their learning by formulating questions related to the study topic expecting a reliable response or clarification of the concept and relevant feedback from Melsyanne.

\subsubsection{Melsyanne Chatbot knowledge}

Chatbot's store information in a knowledge web where the response is retrieved and given to the user of the system. AIML being a ruled-base language means that development of Melsyanne was through a collection of rules known as a datadriven programming paradigm. The rules consisting of two major parts: condition and action. Melsyanne works by selecting one rule which has its specific condition satisfied. She then executes the action of the selected rule. The category element defines the AIML rules. This element also contains pattern and template element. The pattern and template define the conditions and actions. The code below is an illustration of AIML syntax;

$<$ aiml $><$ Category $><$ pattern $>$ WHAT IS AN OPERATING SYSTEM $<$ pattern $><$ template $>$ It is a computer's master control program that controls the computer system $</$ template $></$ category $\rangle\langle$ Category $>\quad<$ pattern $>*$ $</$ pattern $><$ template $><\mathrm{li}>$ Can you say that more clearly? $</$ li $></$ template $><$ template $><$ li $>$ I don't understand $</$ li $></$ template $></$ category $></$ aiml $>$

Melsyanne responds with the word "Hi there" if the learner first says "HELLO." If the user sends information that the chatbot is not familiar with, Melsyanne responds with any of the random action values like "Can you say that more clearly?" or "I don't understand" among other default response.

\subsection{A framework for integrating pedagogical agent in LMS}

The third objective of the study was to design a framework for improving the usability of Learning Management System by integrating a Pedagogical agent. A prototype of a conversational pedagogical agent (Melsyanne) was developed to test if the students can be able to learn by interacting with a digital tutor through asking questions related to a topic covered in their course of study. Just like the LMS the conversational pedagogical agent only requires the internet and web application software like Internet Explorer, Mozilla Firefox, safaris, Opera and Google Chrome among others. The diagram below represents a framework that can be used to integrate pedagogical agent for enhancing the usability of Learning Management System 


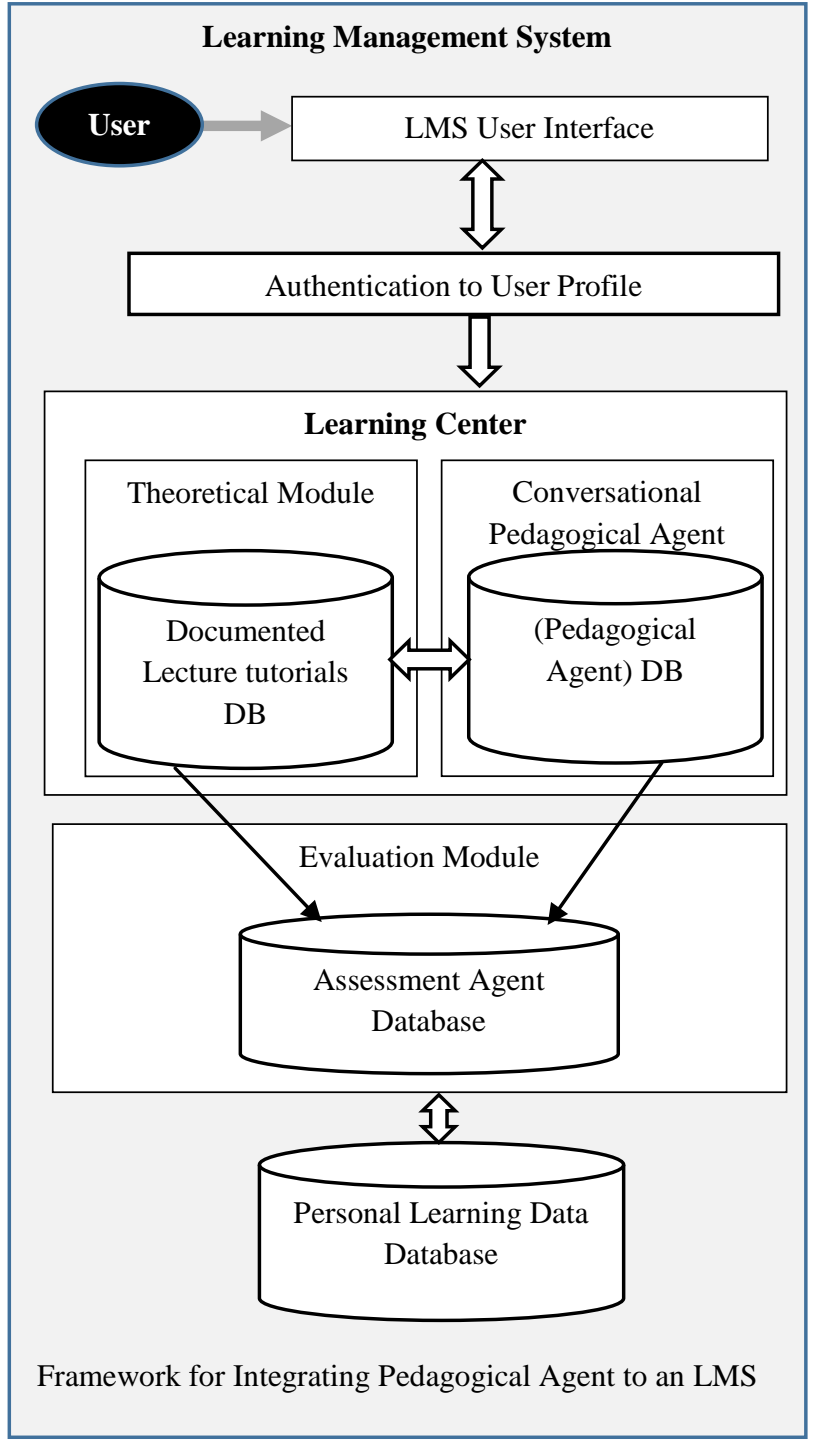

Fig 1: Framework for Integrating Pedagogical agent to improve usability of LMS

The framework (see Figure 1) has the following sections;

\section{The LMS user interface}

The user/student is connected to the online LMS through the systems' interface. To access the courses offered, the student $\operatorname{logs}$ to the LMS by providing their correct credentials.

\section{Learning Center}

The learning center has the following;

i. The theoretical module provides downloadable tutorial files for learning purpose.

ii. The conversational pedagogical agent was integrated to enhance the usability of Learning Management System by supporting instantaneous student-to-instructor interaction in a virtual environment. A Chatbot (Melsyanne) was used as the pedagogical agent to support human-computer interaction between a learner and virtual instructor. Melsyanne Chatbot uses natural language and keyword matching technique to converse with the user.

The student access the conversational pedagogical agent by clicking on a link "chat with Melsyanne" within the LMS.
The student can ask a question or initiate a conversation. Melsyanne reads the user input and searches for specific keywords. If Melsyanne finds a keyword when interacting with the user, then an answer is retrieved from her knowledge web and displayed on the screen. If the user's input had no keyword existing, then Melsyanne provides undefined default response and later record the conversations in the undefined conversation database to enable the administrator to teach Melsyanne on how to respond such questions. A conversational log database stores all conversations between the user and the Melsyanne.

The conversational pedagogical agent (see Figure 2) provides a response to the user by matching the learner's keyword with the information stored in its memory. Interacting with the chatbot has been made possible through its artificial intelligence categorized under natural language processing. The students enjoyed using the application because it motivated their learning and enhance teacher-student interaction through the use of a computer-based pedagogical conversational agent

\section{Assessment agent database}

The database stores questions used for evaluating students during the course learning period. Assessing student is conducted occasionally depending on the dates assigned by the instructor.

\section{Personal learning data database}

Store student's personal information, enrolled courses, messages from the administrator or fellow learners and assessment records among others.

\subsubsection{Melsyanne's Pedagogical objectives}

Melsyanne as a learning aid application program contributing to providing educational information when requested, it provides assistances over traditional teaching methods. The following are Melsysanne's pedagogical objectives in the Learning Management System;

(Pal) Increases student to instructor interaction. The chatbot responds to student's queries by matching keywords with the information stored in its knowledge web.

(Pa2) It is goal oriented and increases student understanding on particular topics. Melsyanne simulates a subject teacher role on how the instructor would communicate or respond to the students. Through active interaction, the students learn at their pace and concentrate more on gaining knowledge on a particular subject.

(Pa3) Makes learning more interesting and motivating. The agent promotes active learning whereby, the student converse with the Melsyanne (virtual tutor) to get first-hand information. The agent provides immediate information to learners hence the students feel motivated to learn.

(Pa4) Add value for teaching. Effective teaching requires the teacher to be physically present when providing instructions to learners and especially when students' need more clarification on areas they failed to understand during their personal study. A virtual tutor fills this gap in a web base learning environment.

\subsubsection{Melsyanne's Pedagogical objectives}

Melsyanne as a learning aid application program contributing to providing educational information when requested, it provides assistances over traditional teaching methods. The 
following are Melsysanne's pedagogical objectives in the Learning Management System;

(Pa1) Increases student to instructor interaction. The chatbot responds to student's queries by matching keywords with the information stored in its knowledge web.

(Pa2) It is goal oriented and increases student understanding on particular topics. Melsyanne simulates a subject teacher role on how the instructor would communicate or respond to the students. Through active interaction, the students learn at their pace and concentrate more on gaining knowledge on a particular subject.

(Pa3) Makes learning more interesting and motivating. The agent promotes active learning whereby, the student converse with the Melsyanne (virtual tutor) to get first-hand information. The agent provides immediate information to learners hence the students feel motivated to learn.

(Pa4) Add value for teaching. Effective teaching requires the teacher to be physically present when providing instructions to learners and especially when students' need more clarification on areas they failed to understand during their personal study. A virtual tutor fills this gap in a web base learning environment.

\subsubsection{Melsyanne's Usability objectives}

A virtual tutor is normally designed to provide effective teaching principles. However, without adequate usability consideration of both the students and instructors, the LMS will rarely be considered as an effective educational system. Usability covers some factors including efficiency, learnability, and satisfaction. It is very important to consider these criteria especially those that involve ease of use and time to learn the system to avoid preventing the students and instructors from adopting the system. Below are some of the usability requirements that are essential for integrating the chatbot to into the LMS

(Usb1) Easy to learn, and (Usb2) Easy to use. The instructor/student can devote most of their teaching/learning a topic rather than master the functionality of the LMS.

(Usb3) Interactive; the agent should support effective and efficient interaction between the learners and course facilitators.
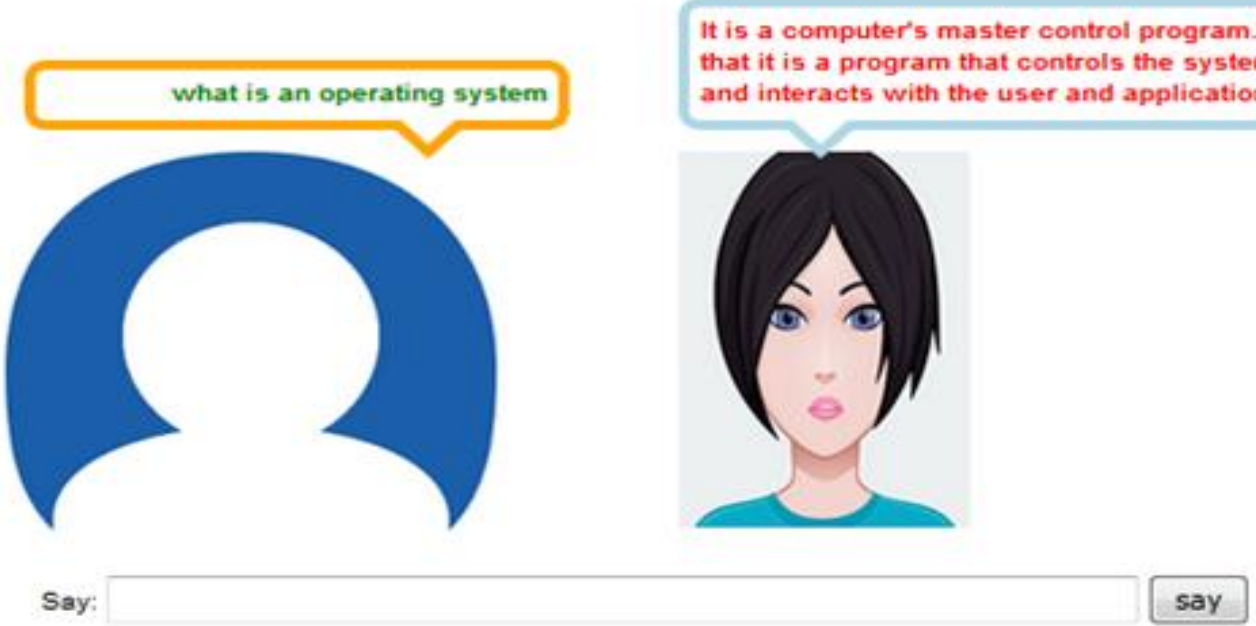

Fig 2: The Diagram Shows how the Student Interacts with a Virtual Tutor (Melsyanne chatbot)

\subsection{Mapping of Usability Measures to the Study Parameters}

Usability is the study of how easy and quick someone can understand how to use a particular computerized system or human-made object. Usability measures include ease of learning, subject satisfaction, and efficiency of use, memorability, and frequency of error. Melsyanne design approach meets various usability requirements as stated below;

Visual representation; Melsyanne has a static image that captures the attention of the user rather than the use of text only for active interaction. When the user communicates with Melsyanne, their message is presented in a green font while the response is provided in a red color. This enables the user to follow the conversation between the tutor and the learner easily. Clear vision increases student to instructor interaction (Pa1), students focus on the topic (Pa2) and are makes learning more interesting $(\mathrm{Pa} 3)$. It is also simple to learn (Usb2) and easy to use (Usb1).
Interactivity; active engagement between the student and the instructor was made possible through training a virtual instructor to simulate how a physical lecture would respond to a student when requested for clarification concerning a particular topic. Increased interactivity between the student and instructor $(\mathrm{Pal}) /(\mathrm{Usb3})$, and supports self-regulated learning $(\mathrm{Pa} 2)$.

Efficiency; Learners experience minimal frustration/obstacles in using the instructional interface. The agent is more than just the visual representation of the instructor and interacting with Melsyanne adds value to learning ( $\mathrm{Pa} 3$ ) and (Pa4) by providing a relevant response the users and enables Human Computer Interaction $(\mathrm{Pal})$ given that fact the that is easy to use (Usb1).

Accessibility; It is easy to access learning materials (Usb2) and $(\mathrm{Pa} 4)$ for a particular topic $(\mathrm{Pa} 3)$. The student can access the system at their convenient time and study at their pace (Pal) while interacting with the virtual instructor $(U s b 3)$.

Consistency; When the user interact (Pal) with the virtual instructor, they get a consistent response and are motivated $\mathrm{Pa}$ ) to continue requesting for more information concerning 
a study topic (Pa4). However, there are some cases where the student might ask for information that Melsyanne has not yet been trained to respond, it will provide a default response or ask a user another question about the topic or change the topic. Due to its simplicity, it is easy to learn and interact with the system (Usb2) and (Usb3)

Learnability; The agent is simple to use (Usb1) and learn (Usb2). It is also goal oriented and focuses on various study topics to increase student understanding of a particular topic (Pa2).

The table below summarizes the mapping between the key study parameters and the key usability dimensions they attempt to satisfy.

Table 1: Mapping usability dimensions to the study parameters

\begin{tabular}{|l|l|l|l|l|l|l|l|}
\hline & $\begin{array}{l}\mathrm{Pa} \\
1\end{array}$ & $\begin{array}{l}\mathrm{Pa} \\
2\end{array}$ & $\begin{array}{l}\mathrm{Pa} \\
3\end{array}$ & $\begin{array}{l}\mathrm{Pa} \\
\text { Usb }\end{array}$ & $\begin{array}{l}\text { Usb } \\
2\end{array}$ & $\begin{array}{l}\text { Usb } \\
3\end{array}$ \\
\hline $\begin{array}{l}\text { Visual } \\
\text { Representati } \\
\text { on }\end{array}$ & $\checkmark$ & $\checkmark$ & $\checkmark$ & & $\checkmark$ & $\checkmark$ & \\
\hline Interactivity & $\checkmark$ & $\checkmark$ & & & & & $\checkmark$ \\
\hline Efficiency & & & $\checkmark$ & $\checkmark$ & $\checkmark$ & & \\
\hline Accessibility & $\checkmark$ & & $\checkmark$ & $\checkmark$ & & $\checkmark$ & $\checkmark$ \\
\hline Consistency & $\checkmark$ & $\checkmark$ & & & & & $\checkmark$ \\
\hline Learnability & & $\checkmark$ & & & $\checkmark$ & $\checkmark$ & \\
\hline
\end{tabular}

The above table indicates that the measure for enhancing the usability of any web-based systems must satisfy usability heuristics mentioned in the study. Therefore, Melsyanne as a visual tutor has developed in a way that it meets the usability dimensions.

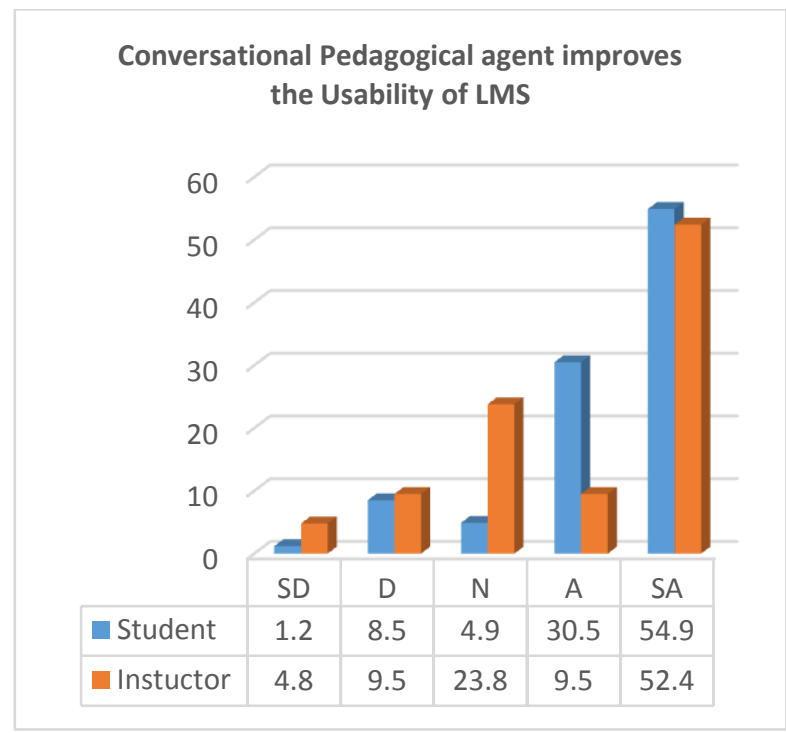

Fig 3: Comparison of the impact of pedagogical agent on improving the usability of LMS according to both the Students and the Instructors
Fig 3, compared the student's and instructor's level of agreement on the impact of the pedagogical agent on improving the usability of an LMS. The study established that both the student and the instructor agreed that a Conversational Pedagogical Agent enhances the usability of the system by making learning more engaging and interactive hence motivating the student to gain more knowledge during their personal studies (85.4\% of students compared to $61.9 \%$ of the instructors).

Table 2: Impact of computer-based pedagogical agent in LMS according to students

\begin{tabular}{|c|c|c|c|c|c|c|}
\hline Impact & SD & D & $\mathbf{N}$ & $\mathbf{A}$ & SA & TOTAL \\
\hline $\begin{array}{l}\text { Improves } \\
\text { usability of } \\
\text { the LMS }\end{array}$ & 1.2 & 8.5 & 4.9 & 30.5 & 54.9 & 100.0 \\
\hline Interactive & 0.0 & 3.7 & 8.5 & 20.7 & 67.1 & 100.0 \\
\hline $\begin{array}{l}\text { Instructors } \\
\text { virtual } \\
\text { presence }\end{array}$ & 9.8 & 2.4 & 20.7 & 28.0 & 39.0 & 100.0 \\
\hline Enjoyable & 1.2 & 1.2 & 4.9 & 18.3 & 74.4 & 100.0 \\
\hline $\begin{array}{l}\text { Provides } \\
\text { hints }\end{array}$ & 17.1 & 30.5 & 14.6 & 26.8 & 11.0 & 100.0 \\
\hline $\begin{array}{l}\text { In control of } \\
\text { learning }\end{array}$ & 1.2 & 8.5 & 15.9 & 39.0 & 35.4 & 100.0 \\
\hline Efficient & 4.9 & 3.7 & 22.0 & 19.5 & 50.0 & 100.0 \\
\hline Motivated & 0.0 & 0.0 & 4.9 & 15.9 & 79.3 & 100.0 \\
\hline $\begin{array}{l}\text { Personalized } \\
\text { learning }\end{array}$ & 4.9 & 6.1 & 20.7 & 29.3 & 39.0 & 100.0 \\
\hline $\begin{array}{l}\text { Instant } \\
\text { response }\end{array}$ & 1.2 & 1.2 & 1.2 & 4.9 & 91.5 & 100.0 \\
\hline Average & 4.1 & 6.6 & 11.8 & 23.3 & 54.1 & 100.0 \\
\hline
\end{tabular}

The study established that the majority of the students $85.4 \%$ agreed that conversational Pedagogical agent improves the usability of LMS compared to $9.8 \%$ who disagreed and $4.9 \%$ who were neutral. The study recognized that the majority of the students $87.8 \%$ agreed that student to instructor interaction was improved through the use of a conversational pedagogical agent as compared to $3.7 \%$ who disagreed and $8.5 \%$ who were neutral. It showed that the majority of them $67.1 \%$ agreed that communicating with the conversational agent made them feel the virtual presence of a digital-tutor compared to $2.4 \%$ who disagreed and $4.9 \%$ were neutral. A majority of the students 92.7\% agreed that chatbot made learning to be more enjoyable compared to $2.4 \%$ who disagreed and $4.9 \%$ were neutral. A majority of the student $47.6 \%$ disagree with the idea that a conversational agent provides hints for a study concept as compared to $37.8 \%$ who agreed and $14.6 \%$ were neutral. The study showed that the majority of the student $74.4 \%$ agreed they would take control of their learning through the assistance of a digital expert compared to $9.8 \%$ who disagreed and $15.9 \%$ who were neutral. The study established that the majority of the students $69.5 \%$ agreed that learning was more 
efficient and effective since they interact with their instructor by asking questions and get immediate response compared to $8.5 \%$ who disagreed and $22 \%$ who were neutral. The study established that the majority of the students $95.1 \%$ agreed digital tutor motivated interactive learning compared to 4.9 who were neutral and none of the students disagreed. The study established that majority of the students $68.7 \%$ agreed that they managed to regulate and personalize their learning as compared to $11 \%$ who disagreed and $20.7 \%$ who were neutral. A majority of them $96.8 \%$ agreed that learning was more interactive since the student could get instant response from the instructor compared to $2.4 \%$ who disagreed and $1.2 \%$ who were neutral. In summary, the majority of the students $85.4 \%$ agreed that integration of conversational pedagogical agent to improve the usability of their LMS would bring many advantages to their educational experience.

\section{SUMMARY OF FINDINGS, CONCLUSION, AND RECOMMENDATIONS}

\subsection{Summary of the major findings}

This section presents a summary of the findings arising from the study.

\subsubsection{Summary of the techniques for enhancing the usability of a Learning Management System} First, the study established that the technique for enhancing the usability of the learning management system mainly relies on (Nielsen, 2012) usability heuristics.

\subsubsection{Summary of Findings on how pedagogical agent can improve the usability of LMS}

The study established that the use of Melsyanne as a virtual tutor improves the usability of a Learning Management System by making learning more interactive through the use of simulated educational conversational programs. Student to instructor communication was made possible by allowing learners freely ask Melsyanne However, a few of their questions did not get the expected answers since Melsyanne had no required answers. Continuous improvement of adding more knowledge to Melsyanne's memory will eliminate the issue of lacking response to queries or unexpected response. The learners' self-paced learning through Melsyanne is made more active, motivating, interesting and effective.

\subsubsection{Summary of a framework for integrating pedagogical agents in LMS}

The framework represents a logical view of integrating a conversational agent to an LMS (Moodle). The study established that the Learning Management System allows the student to authenticate into the LMS and access their personal profile through the web user interface. The student receives the learning content in either a downloadable documented file (theory module) or by conversing with a digital tutor (Pedagogical Conversational Agent). The student can interact with a digital tutor (Melsyanne) to gain more information about the topic of study. The assessment agent evaluates students and their results recorded in the learners' personal database.

\subsubsection{Summary of Findings on the impact of computer-based pedagogical agents in LMS}

The study established that computer-based pedagogical agents have a great impact on the usability on the Learning Management System. First, the learning is more interesting when using interactive programs. Secondly, the students are motivated to engage the virtual tutor when they need an immediate response and more clarification concerning a topic they are studying. Lastly, learning is not only made easy but interesting hence enabling the student to become more effective and knowledgeable in their field of study.

\subsection{Conclusions of the study}

The purpose of the study was to develop a framework for improving the usability of Learning Management System by integrating pedagogical agent. The study established that most of the students enrolled in the Learning Management System for studies peruse through the documented learning tutorials (commonly referred to as handouts) to master the theoretical concepts of technical units. At times students' ask their course facilitator questions concerning a study concept but they don't get an immediate response. On many occasions, learners fail to get someone to take them through the technical concepts that need the presence of an instructor to assist them to master a task or understand a topic. Even though most course management systems allow learners download course material and evaluate students' performance, there is a need for the student to interact with their facilitator and get an immediate response to make their learning more active and effective. Therefore, digital tutors through the use of conversational pedagogical agent like Melsyanne can be integrated into the course delivery systems to increase student to instructor interaction, make studies more enjoyable and motivate the student to take control of their learning. The study also establishes that usability heuristics are the key measurements to consider when developing an effective conversational pedagogical agent improving the usability of LMS. Therefore, use of Melsyanne as a virtual instructor (Pedagogical Agent) to a large extent improves the usability of Learning Management System.

\subsection{Recommendations}

About the findings, the study recommends as follows: First, the higher learning institutions should strategically plan on integrating conversational agents with speech capabilities to allow audio input and provide an audio response to learners' inquiries. The conversational pedagogical agent will make communication more active and engaging. Second, the institutions should consider the allocation of virtual labs through the use of simulated 3D programs to facilitate fundamental practice to the technical task. Third, let the agents not only be animated but interactive in a way that they are capable of indicating the learning progress and capability of performing the technical task.

\subsection{Suggestions for further research}

The study recommends the following further research studies: A study should be undertaken on the how pedagogical agents improves learning and technical capabilities of the students despite the fact that they are virtual tutors' demonstrating tasks performed in real life environment. 


\section{REFERENCES}

[1] Nielsen, J. 2012. Usability 101: Introduction to Usability.

[2] Dias, S., Diniz, A., and Hadjileontiadis, J. 2013. Towards an Intelligent Learning Management System Under Blended Learning: Trends, Profiles, and Modeling Perspectives. ASpringer Science \& Business Media.

[3] Kats, Y. 2013. Learning Management Systems and Instructional Design: Best Practices in Online Education. Idea Group Inc.

[4] Cheok. M., and Wong, S. 2015. Predictors of E-Learning Satisfaction in Teaching and Learning for School Teachers: A Literature Review. International Journal Of Instruction, 85

[5] Johnson, W., and Richel, J. 1998. An Animated Pedagogical Agent for Procedural Training in a Virtual Environment. SIGART Bulletin, 16-21.

[6] Baylor, A. L. 2006. Investigating Multiple Pedagogical Inspired Learning Nuggets. Educational Technology and Society.

[7] Alavi, M. 1999. Knowledge Management Systems: Issues, Challenges, and Benefits; Communication of the Association for Information Systems.

[8] Asunka, S. 2014. Web-based Learning Management Systems in Developing Countries, Igi Global.

[9] Kipkurui, K., Wanyembi, G., and Ikoha, P. 2014. Evaluating Usability of E-Learning Systems In Universities.

[10] Phye, G. D., and Andre, T. 1989. Delay-retention effect: Attention, perseveration, or both? Contemporary Educational Psychology, 14, 173-185.

[11] Baker, J. Grant, s., and Morlock, L. 2008. The teacherStudent Relationship as a Developmental Context for Children with Internalizing or Externalizing Behavior Problems. School Psychology Quarterly, 23(1), 3-15.

[12] O'Connor, E. E., Dearing, E., and Collins, B. A. 2011. Teacher-Child Relationship and Behavior problem trajectories in elementary school. American Educational Research Journal, 48(1), 120-162.

[13] Silver, R. B., Measelle, J. R., Armstrong, J. M., and Essex, M. J. 2005. Trajectories of classroom externalizing behavior: Contributions of child characteristics, family characteristics, and the teacherchild relationship during the school transition. Journal of School Psychology, 43(1), 39-60.

[14] Thuseethan, S., \& Kuhanesan, S. Effective Use of Human-Computer Interaction in Digital Academic Supportive Devices. International Journal of Science and Research, 3(6), 2014, 388-392.

[15] Tselios, N., Avouris, N., and Komis, V. 2008. The effective combination of hybrid usability methods in evaluating educational applications of ICT: Issues and challenges. Education and Information Technologies, 13(1), 55-76.

[16] Shackel, B. Usability-context, Framework, Definition, Design, and Evaluation. Shackel, B. and Richardson, S., Ed. Human Factors for Informatics Usability. Cambridge, UK, Cambridge University Press, 1991, 21 37.

[17] Chang C. 2008. Faculty Perceptions and Utilization of a Learning Management System In Higher Education. ProQuest.

[18] Hetsevich, I. 2014. How to improve eLearning course design usability by adopting the 10 Usability Heuristics, link, http://elearningindustry.com/how-to-improveelearning-course-design-usability-by-adopting-the-10usability-heuristics.

[19] Atolagbe, T. 2002. E-learning: the use of components technologies and artificial intelligence for management and delivery of instruction. Paper presented at ITI. Proceedings of the 24th International Conference on Information Technology Interfaces; 2002. p. 121-128.

[20] Ivanovic, M. and Jain L, 2013. E-Learning Paradigms and Applications: Agent-based Approach, $150-155$.

[21] Jafari, A. 2002. Conceptualizing Intelligent Agents for Teaching, and Learning.

[22] Savin-Baden, M. 2015. Rethinking Learning in an Age of Digital Fluency. Routledge.

[23] Buchem, L. 2014. Learning and Diversity in the Cities of the future. Logos Verlag Berlin $\mathrm{GmbH}$

[24] Johnson, W., Rickel, Jeff., and Lester. J. 2000. Animated Pedagogical Agents: Face-to-Face interactions in interactive environments. International Journal of Artificial Intelligence in Education, 11, 47-78.

[25] Erickson, K. A. 1996. The Acquisition of Expert Performance: An Introduction to some of the Issues. In K. A. Erickson (E.D), The road to excellence: Aquisition of expert performance in the arts sciences, sports, and games. Hillsdale, NJ: Erlbaum.

[26] Al-Zoube, M. 2009. E-Learning on the Cloud, International Arab Journal of e-Technology, Vol 1, No $2,50-63$

[27] Conati, C. and Zhao, X. 2004. Building and Evaluating an Intelligent Pedagogical Agent to Improve the Effectiveness of an Educational Game. IUI '04 Proceedings of the 9th International Conference on Intelligent user interfaces.

[28] Zadrozny, W., Budzikowska, M., and Kambhatla, N. 2007. Natural language dialogue for personalized interaction. 
[29] Dehn, D. and Mulken, S. 2000. The impact of Animated interface: a review of empirical research. International Journal of Human-Computer Studies, 1-22.

[30] Lester, J. B. K. 2004. Conversational Agents. USA: CRC Press LLC.

[31] Augello, A. Saccone, G., Gaglio, S., and Pilato, G. 2008. Humorist Bot: Bringing Computational Humour in a Chat-Bot System. Complex. Intelligent and Software Intensive Systems, 2008. CISIS 2008. International Conference on.
[32] Veletsianos, G., Scharber, C., and Doering, A. 2008. When sex, drugs, and violence enter the classroom: Conversations between adolescents and a female pedagogical agent. Interacting with computers, 292-301.

[33] Russell, S., and Norvig, P. 2010. Artificial Intelligence: A Modern Approach; Third Edition. New Jersey: Pearson Education, Inc.

[34] Kumar, E. 2011. Natural Language Processing. New Delhi: I.K International Publishing House Pvt. Ltd. 